\title{
Reform and Development of Multimedia Teaching Methods in Foreign Language Courses at Colleges and Universities
}

\author{
Li Yun \\ Xi'an University School of Foreign Studies, 710065
}

Keywords: College foreign language courses; Multimedia teaching; Change; Development

\begin{abstract}
For multimedia teaching methods in foreign language courses at colleges and universities, it is necessary to combine the characteristics of multimedia courseware with teaching and pay attention to some problems regarding usage so as to truly play the advantages of multimedia teaching equipment and achieve the ideal effect of teaching.

Traditional way of teaching is too simple, so it is necessary to use multimedia teaching methods for foreign language teaching and carry out personalized teaching according to students' characteristics so as to improve the effectiveness of teaching. Meanwhile, it is necessary to cultivate students' independent learning capacity combined with the actual teaching and with new teaching methods.
\end{abstract}

\section{Problems to be noted in Preparing Teaching Courseware in College Foreign Language Courses}

Give play to the Advantages of Multimedia Teaching and Take Students as the Leading Role in the Classroom

With the progress of the times, traditional foreign language teaching can no longer adapt to the modern teaching contents. The quality of classroom teaching depends on students' learning attitude and has little to do with the teaching equipment. Teaching equipment is only an auxiliary tool during the teaching, but the key lies in foreign language teachers. While using multimedia technology for teaching, the first thing to consider is when to use this technique. Then, it has to be noted that all these are only auxiliary tools of this technique, and the demands of the main body of classroom teaching should not be ignored. Students should be given enough time for self-reflection and to absorb the learned knowledge so as to produce more effective teaching effect. For the use of modern teaching devices, it is necessary to combine the students' learning role, teachers' aids and the multimedia so as to play the role of teaching. In this way, students can better accept relevant knowledge and contents. Besides, multimedia technologies can present a variety of contents and involve a wide range of fields, so it can make the dull classroom teaching become lively and vivid, and the knowledge can also become impressive. However, attention should also be paid to the demonstration effect of these video images. For example, the division of the functional areas of the screen, the design of font, the collation of words and pictures and the color and size of front are all important. If the video color is too dazzling, it will give people a sense of visual fatigue, and if the font is too small, students sitting in the back rows can hardly see the contents displayed on the screen. In addition, clarity is also critical. If the contents are vague, it can only make the teaching effect worse. Besides, the design of each courseware background should be in line with the classroom learning contents so as to make it coordinated. In short, it is necessary to determine the suitable theme and color according to different teaching contents and decide on the order to play the videos according to students' thinking order. The preparation for both courseware and contents should be reasonable so as to achieve better teaching effects and attract students' attention.

Pay attention to controlling the speed of page replacement

Multimedia technologies are used for teaching because multimedia technologies can effectively improve the classroom teaching and make it easier for students to master massive teaching information. However, it should be noted that if students stare at the screen for a long time during teaching, they may easily have visual fatigue. In this case, once the teacher lectures too fast or the page replacement is too fast, students can hardly catch up with the teachers. Then, they will not 
have enough time to digest what they have learned, nor can they be able to well record the knowledge taught at class. Multimedia technologies should be used in teaching because it can affectively improve classroom teaching and easily grasped. Besides, multimedia can contain a large amount of teaching information. However, it should be noted that if students stare at the screen for a long time, they can easily have eye fatigue. Then, once the teacher lectures too fast or the page replacement is too fast, students can hardly keep up with the teacher. Then, they will not have enough time to digest what they have learned and there is no way to keep a good record of the knowledge taught at class. In this case, students will feel that the classroom teaching speed is too fast and they cannot keep up with the teacher, thus they will have a negative attitude. Therefore, teachers should pay attention to this while preparing for the class and change the pages at an appropriate speed. Besides, teachers should pay attention to students' learning status. They can pause for a while to help students digest knowledge and record knowledge points. Besides, for the knowledge on each page, after lecturing, teachers should set aside a little time for students to buffer for a while so that the student can keep up with the pace and establish good learning attitude. Thus, this learning method is taught to be useful. Therefore, while preparing the courseware, teachers need to consider many factors. Instead of just completing the teaching tasks, teachers should help students find the fun of learning. Only when students learn in a relaxing environment can they quickly master all the knowledge points taught at class. Step-by-step teaching is the most efficient way. In addition, the teacher can also ask students to copy the courseware into their own hardware and then review relevant knowledge points after class. Or, while lecturing with the help of multimedia technologies, the teacher can slow down the speed of switching pages, but they need to pay attention to whether the students have absorbed the knowledge. Some students may only accept the knowledge, but they do not completely master them. Therefore, the teacher must pay attention to classroom teaching design and consider these issues in design, master the teaching speed and make suitable adjustment according to the actual teaching so as to effectively solve these problems.

\section{Courseware Production should be Consistent With the Equipment}

Before the lecture, the teacher should also fully understand the basic functions and configurations of the teaching equipment and make preparation in advance. Sometimes, although teachers have already well prepared the teaching courseware, this courseware cannot be used in teaching equipment, or the information is distorted, or the pictures displayed are rather vague or even disillusioned. Therefore, the teaching effect is naturally poor. Therefore, in making courseware, the courseware must be consistent with the teaching equipment, and the teacher should make teaching courseware according to the demands of the equipment so as to better teach.

\section{Pay Attention to the Virtuous Circle in Teaching}

\section{Constantly Optimize and Pursue Excellence}

Preparation before class, teaching effect and finishing work after class are all crucial. In order to enrich classroom teaching contents, attract students' attention and improve their interest in learning, it is necessary to design interesting and vivid teaching contents so as to arouse their passion for learning. In addition, while making courseware for teaching, the teacher should make constant optimization and pursue excellence so as to make better courseware. For multimedia teaching, the teacher must ensure the pictures are vivid, the contents are colorful and the logic is smooth during preparation so as to help students understand the knowledge more intuitively and gradually accept each knowledge point. In order to make beautiful courseware, many teachers spend a large amount of time and energy on the courseware, thus, it can be seen that teachers are also one of the very crucial factors in teaching.

\section{Enrich Courseware Contents and Make Courseware More Interesting}

Modern teaching methods can effectively make up for the deficiencies in traditional teaching. Therefore, in order to diversify the teaching, multimedia technology is indispensable. It can well solve the problems in traditional teaching and demonstrate the advantages of modern teaching. Besides, multimedia technologies can demonstrate a wide range of teaching contents, and the pictures that can demonstrate knowledge are also vivid and catch students' attention. However, it 
should be noted that multimedia technology is just an auxiliary teaching tool. Therefore, teachers should also pay attention to their teaching methods while preparing courseware without depending too much on multimedia technology, and they should also demonstrate their own teaching styles. Besides, they should design featured teaching contents according to the teaching contents. Particularly, different teaching contents should be demonstrated with different styles and ways so as to demonstrate more teaching styles, which is also the advantage of diversified teaching. Equipment used in teaching can only serve as an auxiliary tool and cannot be used as the main body of teaching. Besides, different courseware have different production methods and use, so it is necessary to combine auxiliary tools with teaching methods so as to better demonstrate the learning contents, enrich the classroom teaching and improve students' learning efficiency and guarantee the classroom teaching efficiency.

\section{Pay Attention to the Interaction Between Teachers and Students}

While using multimedia technology for teaching, teachers cannot solely rely on teaching equipment. In addition, many teachers just regard themselves as a "switcher". They do not pay attention to their role as a teacher nor students' learning status. Therefore, in classroom teaching, teachers should pay attention to the activity of the classroom and teacher-student interaction. Teaching equipment, no matter how advanced they are, are just an auxiliary tool. Finally, it is the teacher that decides on the teaching quality. Therefore, in multimedia teaching, teachers should not only pay attention to operating the computer to switch the knowledge pages, but should also pay attention to the explanation of each knowledge point and even the current classroom teaching atmosphere and effect, such as students' learning status, classroom atmosphere and students' understanding of the knowledge. In addition to interpreting some knowledge, the teacher should also pay attention to students' mastery of knowledge. In addition, in teaching design, the teacher can also create some interesting scenarios for students to interact and express their opinions. Or, students can be allowed to discuss some hot topics and express their own opinions. All these can improve students' passion for learning. And students can also be encouraged to participate in these. After all, there is a huge gap between multimedia teaching and traditional classroom teaching. Therefore, in order to using the advantages of multimedia technologies, the teacher should also notice their disadvantages and pay attention to interaction between students just like in general classroom teaching. And teachers can also effectively combine this with using multimedia technology for teaching so as to obtain better teaching effect.

\section{Pay Attention to Understanding in the Spiritual Field}

Any subject involves a wide range of fields, including other subjects. English belongs to the language discipline, so its demonstration is also the sublimation of language. Therefore, in addition to basic teaching methods, teachers should also pay attention to spiritual education, i.e., in order to improve the English classroom teaching effect and achieve a more ideal status, attention must be paid to teachers' own status. As the deliverer of English, English teachers should guide students, so they must reach a certain level in terms of their own English proficiency. Besides, while using multimedia technologies for teaching, teachers will prepare some courseware, and the contents, teaching scenarios and logic of the courseware are all ways to demonstrate the teacher's spiritual field. Therefore, teachers are the disseminator of knowledge. In order to improve students' understanding and their spiritual realm, it is necessary to make them feel the life philosophy and reflections of the spiritual field. Multimedia technologies are also a kind of medium to spread knowledge. It demonstrates humanistic knowledge and culture and also promotes the development of education. And teachers need to renew themselves with the time and constantly renovate their teaching methods and approaches in an all-round way. Besides, they need to pay attention to improving their comprehensive quality and professional ability. During preparation, teachers need to make the courseware exquisite and try to integrate the knowledge and contents in textbook into courseware so as to achieve a unity of form and contents. Teachers must pay attention to each detail and they are the representative of educating people. The so-called teaching refers to teach knowledge to students, and learning refers to learn to behave well. Therefore, teachers not only impart knowledge, but also embody thoughts and morality. Thus, teachers should not ignore 
teaching at the spiritual field. Besides, much knowledge is taught to students subtly. This infectious teaching method can be used to product very excellent teaching effect. Therefore, teachers must pay attention to their own spiritual reflection and improve their teaching methods accordingly, and reasonably use multimedia teaching equipment in teaching.

\section{Conclusion}

In short, it is far from enough to rely solely on multimedia technology for teaching, as it requires both intellectual and mental comprehensions. Although multimedia teaching has many advantages and helps to improve classroom teaching, teachers cannot solely rely on this teaching method, but should pay attention to their role and functions as a teacher. Besides, teachers should apply their teaching capacity in classroom teaching and combine multimedia teaching equipment for more effectively classroom teaching so as to improve the classroom teaching quality.

\section{References}

[1] Yao Jing. Study on the Integration of College Foreign Language Teaching and Multimedia Resources from the Perspective of Memetics [J]. Journal of Foreign Languages, 2013, (02):120-125.

[2] Niu Yuehui. Reform and Development of Multimedia Teaching Methods in Foreign Language Courses at Colleges and Universities [J]. Modern Education Science,2010,(11):96-98.

[3] Ma Congli. Analysis of Multimedia Assisted Foreign Languages Teaching at Colleges - Taking "Japanese as the Second Language" as an Example [J]. Journal of Shaanxi Radio \& TV University, 2015, (03):61-63.

[4] $\mathrm{Na}$ Min. Statistical Analysis on the Research of Multimedia Assisted Foreign Language Teaching in China [J]. Journal of Inner Mongolia Normal University (Philosophy and Social Sciences Edition), 2016, (S1):154-158. 